\title{
DISIPLIN KERJA, KESEHATAN DAN KESELAMATAN KERJA BERPENGARUH TERHADAP PRODUKTIVITAS KERJA KARYAWAN SARIASIH GARMENT
}

\author{
Briyan Artha Ginting 1 \\ I Wayan Suana ${ }^{2}$ \\ ${ }^{1,2}$ Fakultas Ekonomi dan Bisnis Universitas Udayana (Unud), Bali, Indonesia \\ email: cesenmangat48@gmail.com
}

\begin{abstract}
ABSTRAK
Produktivitas merupakan suatu kemampuan untuk mencapai tugas-tugas tertentu sesuai dengan standar yang telah ditentukan. Perusahaan harus menciptakan lingkungan kerja yang aman dan nyaman guna memotivasi karyawan agar mereka terdorong untuk melaksanakan tugasnya dan dapat meningkatkan produktivitas perusahaan secara menyeluruh. Tujuan penelitian adalah untuk menjelaskan pengaruh disiplin kerja, kesehatan dan keselamatan kerja terhadap produktivitas kerja karyawan Sariasih Garment dengan 51 orang sebagai sampel, menggunakan metode sampel jenuh. Pengumpulan data dilakukan melalui observasi, wawancara dan kuesioner dan dianalisis dengan regresi linier berganda. Berdasarkan hasil analisis, disiplin kerja, kesehatan kerja dan keselamatan kerja berpengaruh positif dan signifikan terhadap produktivitas kerja karyawan. Diharapkan perusahaan memperhatikan kepatuhan karyawan terhadap peraturan dalam melakukan pekerjaannya dan perusahaan mampu membuat lingkungan kerja yang aman, nyaman dan bersih untuk karyawan para karyawan memiliki semangat dan mendapatkan perlindungan pada saat bekerja sehingga karyawan mampu meningkatkan produktivitas kerjanya guna menciptakan hasil kerja yang maksimal
\end{abstract}

Kata kunci : Produktivitas kerja, Disiplin kerja, Kesehatan dan Keselamatan kerja

\begin{abstract}
Productivity is the ability to achieve certain tasks in accordance with predetermined standards. Companies must create safe work environment to motivate employees so that they can increase overall company productivity. Purpose of the study is to explain the effect of work discipline, occupational health and safety on the work productivity of Sariasih Garment employees with 51 people as samples, using saturated sample method. Data collected through observation, interviews and questionnaires and analyzed by multiple linear regression. Based on the results, work discipline, occupational health and work safety have positive and significant effect on employee work productivity. It is expected that company pays attention to employees' compliance with regulations in doing their jobs and the company is able to create a safe, comfortable and clean work environment. Employees have enthusiasm and protection while working so that employees are able to increase work productivity in order to create maximum work results.
\end{abstract}

Keywords: work productivity, work discipline, work health and safety 


\section{PENDAHULUAN}

Dunia industri sudah berkembang pesat di seluruh dunia termasuk di Indonesia. Apalagi saat ini sudah memasuki industri 4.0 dimana persaingan akan semakin. Salah satu cara yang dapat dilakukan oleh perusahaan agar dapat bertahan di dalam persaingan tersebut adalah dengan cara meningkatkan produktivitas karyawan (Hanaysha, 2016). Sultana et al. (2015) menyebutkan tujuan utama dari peningkatan produktivitas kerja agar karyawan mampu bekerja lebih efektif, efisien, dan produktif. Seorang karyawan yang produktif adalah karyawan yang handal dan mampu menghasilkan barang atau jasa sesuai dengan standar kualitas yang telah ditetapkan dengan waktu yang sesingkat-singkatnya. Produktivitas kerja di suatu perusahaan dipengaruhi oleh beberapa faktor, salah satunya adalah kesehatan dan keselamatan kerja (Prayitno \& Palupi, 2015). Penurunan produktivitas dapat disebabkan oleh proses kerja yang terputus, peralatan kerja yang kurang memadai, kurangnya motivasi, lingkungan yang tidak kondusif dan lain - lain (Ofoegobu et al., 2015)

Menurut Umeokafor et al. (2015) kesehatan dan keselamatan kerja sangat perlu diperhatikan karena merupakan daerah interdisipliner yang melibatkan perlindungan kesehatan dan keselamatan kerja kepada karyawan di suatu perusahaan dan hal-hal yang mungkin terkena dampak langsung maupun secara tidak langsung oleh kegiatan di tempat kerja.

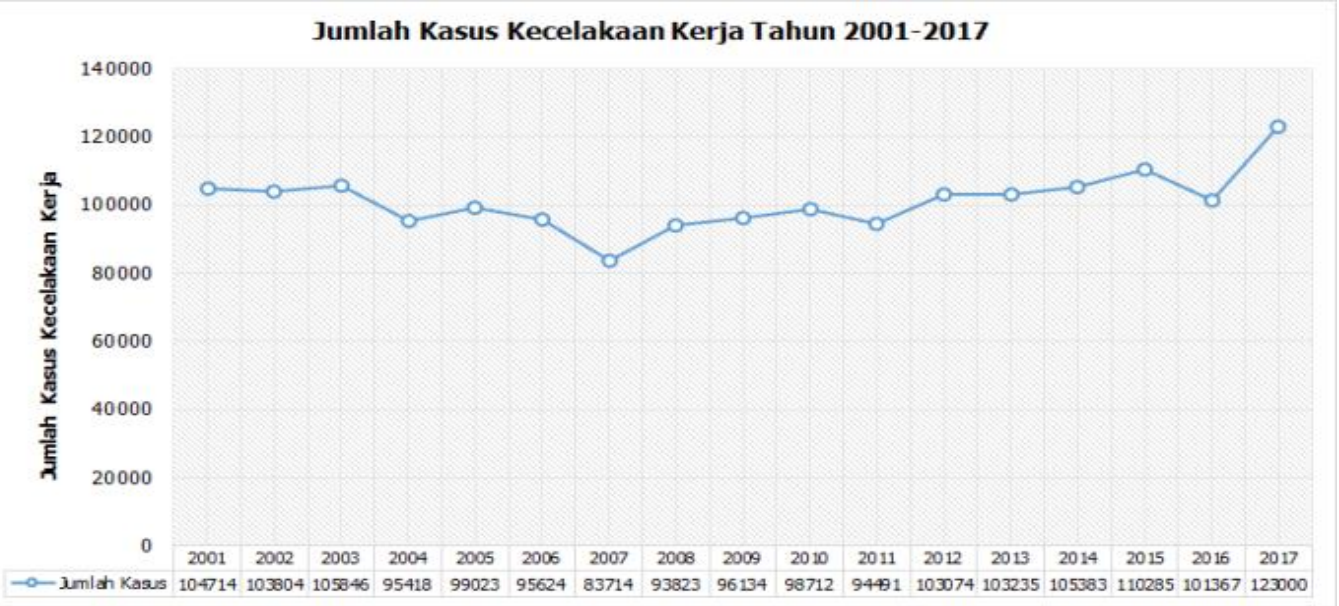

Gambar 1. Jumlah Kasus Kecelakaan Kerja Tahun 2001-2017

Sumber: Data Diolah, 2019

Periode Desember 2018, menyatakan bahwa ada 12 kasus kecelakaan kerja setiap jamnya di Indonesia. Dalam hal ini jika jumlah kasus per tahun tersebut kita bagi per hari dan per jam. Bukan angka yang sedikit dan menandakan masih minimnya perhatian kita dalam implementasi kesehatan dan keselamatan kerja. Semua ini mengindikasikan masih rendahnya aspek kesehatan dan keselamatan kerja di Indonesia. Oleh karena itu kesehatan dan keselamatan kerja belum mendapatkan perhatian dan masih menjadi budaya di tengah masyarakat Indonesia.

Dalam beberapa tahun belakangan ini Sariasih Gament mengalami penurunan produktivitas karyawannya yang terjadi akibat kecelakaan kerja di Sariasih Garment yang dapat dilihat dalam Tabel 1. 
Tabel 1.

Jumlah Kecelakaan Kerja Sariasih Garment Tahun 2016-2018

\begin{tabular}{|c|c|c|c|c|c|}
\hline No & Tanggal & $\begin{array}{l}\text { Jenis } \\
\text { Cidera }\end{array}$ & $\begin{array}{l}\text { Jumlah } \\
\text { Kecelakaan } \\
\text { Kerja }\end{array}$ & Deskripsi Kecelakaan & $\begin{array}{c}\text { Hari } \\
\text { yang } \\
\text { Hilang }\end{array}$ \\
\hline 1 & Januari 2016 & Ringan & 2 orang & $\begin{array}{l}\text { Pada saat proses penjahitan } \\
\text { tangan terkena patahan jarum } \\
\text { mesin jahit. }\end{array}$ & 2 \\
\hline 2 & Mei 2016 & Sedang & 3 orang & $\begin{array}{lll}\text { Karyawan mengalami } & \text { sesak } \\
\text { napas karena } & \text { tidak } \\
\text { menggunakan masker pada } \\
\text { saat proses pengecekan kain. }\end{array}$ & 9 \\
\hline 3 & Agustus 2016 & Ringan & 4 orang & $\begin{array}{l}\text { Pada saat proses penjahitan } \\
\text { tangan terkena mesin jahit. }\end{array}$ & 4 \\
\hline 4 & April 2017 & Sedang & 2 orang & $\begin{array}{l}\text { Terjatuh pada saat sedang } \\
\text { mengambil potongan kain } \\
\text { karena licin. }\end{array}$ & 6 \\
\hline 5 & $\begin{array}{l}\text { September } \\
2017\end{array}$ & Berat & 1 orang & $\begin{array}{lrr}\text { Pada saat proses pemotongan } \\
\text { tangan terkena } & \text { mesin } \\
\text { pemotong } & \text { karena } & \text { tidak } \\
\text { berhati-hati. } & & \end{array}$ & 7 \\
\hline 6 & Januari 2018 & Ringan & 3 orang & $\begin{array}{l}\text { Pada saat pemasangan kancing } \\
\text { tangan tergencet mesin jahit. }\end{array}$ & 3 \\
\hline 7 & Mei 2018 & Berat & 2 orang & $\begin{array}{l}\text { Pada saat proses pemotongan } \\
\text { tangan terkena mesin } \\
\text { pemotong dan hampir putus. }\end{array}$ & 30 \\
\hline 8 & Mei 2018 & Ringan & 1 orang & $\begin{array}{l}\text { Pada saat proses penjahitan } \\
\text { tangan terkena patahan jarum } \\
\text { mesin jahit. }\end{array}$ & 1 \\
\hline 9 & Agustus 2018 & Ringan & 1 orang & $\begin{array}{l}\text { Terkena sengatan arus listrik } \\
\text { karena tangan yang basah } \\
\text { sesudah dari kamar mandi. }\end{array}$ & 1 \\
\hline 10 & $\begin{array}{l}\text { Nopember } \\
2018\end{array}$ & Ringan & 3 orang & $\begin{array}{l}\text { Pada saat proses penjahitan } \\
\text { tangan terkena patahan jarum } \\
\text { mesin jahit. }\end{array}$ & 3 \\
\hline 11 & $\begin{array}{l}\text { Desember } \\
2018\end{array}$ & Ringan & 2 orang & $\begin{array}{l}\text { Pada saat proses penjahitan } \\
\text { tangan terkena patahan jarum } \\
\text { mesin jahit }\end{array}$ & 2 \\
\hline
\end{tabular}

Sumber: Sariasih Garment, 2019

Kecelakaan kerja yang terjadi pada Tabel 1. diatas disebabkan oleh berbagai faktor, baik itu faktor yang berkaitan dengan lingkungan pekerjaan, seperti mesin-mesin, alat-alat pekerjaan dan bahan-bahan yang digunakan dalam proses produksi, maupun. Selain itu juga faktor yang berasal dari karyawan sendiri, seperti bekerja tanpa alat pelindung diri (APD) berupa sarung tangan, masker, celemek, thimble jahit, dan merokok di dekat bahan yang mudah terbakar. Kecelakaan-kecelakaan tersebut tentu mengindikasikan bahwa pelaksanaan program keselamatan kerja masih belum optimal dilakukan oleh pihak Sariasih Garment. 
Tabel 2.

Jumlah Produktivitas Kerja Sariasih Garment Tahun 2016-2018

\begin{tabular}{lclclc}
\hline \multicolumn{1}{c}{ 2016 } & Capaian & \multicolumn{1}{c}{$\mathbf{2 0 1 7}$} & Capaian & \multicolumn{1}{c}{$\mathbf{2 0 1 8}$} & Capaian \\
\hline Januari & 10064 & Januari & 9508 & Januari & 8502 \\
Februari & 10584 & Februari & 9709 & Februari & 8764 \\
Maret & 10904 & Maret & 9629 & Maret & 8673 \\
April & 10689 & April & 10255 & April & 9486 \\
Mei & 11056 & Mei & 10579 & Mei & 10280 \\
Juni & 11960 & Juni & 9705 & Juni & 9566 \\
Juli & 12689 & Juli & 10690 & Juli & 8453 \\
Agustus & 11870 & Agustus & 11060 & Agustus & 9492 \\
September & 11359 & September & 10692 & September & 8919 \\
Oktober & 11086 & Oktober & 10396 & Oktober & 9082 \\
November & 12095 & November & 10649 & November & 9330 \\
Desember & 16048 & Desember & 10476 & Desember & 8602 \\
\hline
\end{tabular}

Sumber: Sariasih Garment, 2019

Berdasarkan Tabel 2. menunjukan bahwa terjadi penurunan produktivitas kerja Sariasih Garment dari tahun 2016-2018 akibat kecelakaan kerja yang dari tahun 2016-2018 meningkat dan menyebabkan hilangnya hari kerja karyawan pada Tabel 1. Ini semua mengindikasikan bahwa jika kesehatan dan keselamatan kerja menurun maka produktivitas kerja juga akan menurun.

Kesehatan di Sariasih Garment juga belum terlalu diperhatikan. Terbukti dari observasi yang dilakukan, masih ada beberapa karyawan yang mengerjakan pekerjaanya tidak menggunakan masker padahal kain yang digunakan untuk proses produksi tersebut mengandung debu dan bisa menimbulkan penyakit pernapasan apabila dihirup oleh manusia. Hal tersebut didukung oleh penelitian Sulfikar (2015) yang menyatakan bahwa gangguan sistem pernapasan dapat timbul dalam lingkungan pekerjaan yang mengandung debu industri, terutama pada kadar yang cukup tinggi. Berdasarkan hasil wawancara dengan 11 orang karyawan yang bekerja pada Sariasih Garment menyatakan bahwa kondisi tubuh mereka mulai gampang lelah karena mereka sering mengalami sakit punggung yang disebabkan oleh posisi kerja yang dilakukan secara terus menerus dengan waktu kerja yang lama dan tidak ada tindakan dari perusahaan.

Saleh (2018) menyatakan bahwa tanpa disiplin karyawan yang baik, sulit bagi perusahaan untuk dapat mencapai hasil yang optimal. Berdasarkan observasi yang dilakukan peneliti, masih banyak karyawan yang terlambat pada saat jam masuk kerja ataupun pulang lebih awal sebelum jam kerja berakhir dengan alasan yang tidak dapat diterima. Karyawan juga sering menggunakan jam kerja untuk mengobrol sesama karyawan pada saat bekerja. Karyawan juga masih sering tidak mentaati peraturan yang ada karena kurangnya kontrol dari pimpinan. 
Hilangnya disiplin akan berpengaruh terhadap produktivitas kerja karyawan (Gubler et al., 2016).

Peran disiplin kerja, kesehatan, dan keselamatan kerja menjadi pertimbangan untuk perusahaan agar mampu meningkatkan produktivitas kerja karyawan untuk jangka waktu yang lama guna mencapai tujuan perusahaan. Dengan menjaga kedisiplinan karyawan yang tinggi dari karyawan akan membantu perusahaan mencapai tujuannya dengan cepat. Dengan program kesehatan dan keselamatan kerja yang ada diharapkan karyawan akan termotivasi karena memiliki rasa aman dan nyaman pada saat bekerja sehingga dapat meningkatkan produktivitas kerjanya. Adeyeye et al. (2015) yang menyatakan bahwa tidak ada pengaruh antara disiplin kerja terhadap produktivitas. Hal ini terjadi karena pada dasarnya sifat baik seorang individu adalah abstrak dan tidak bisa diamati. Jadi akan menjadi sebuah penelitian yang menarik karena sudah banyak teori dan penelitian yang menyatakan bahwa disiplin kerja, kesehatan dan keselamatan kerja berpengaruh terhadap produktivitas kerja tetapi ada sebuah research gap dan penelitian yang menyatakan bahwa disiplin dan kesehatan kerja tidak berpengaruh terhadap produktivitas kerja.

Tujuan penelitian berdasarkan rumusan masalah diatas adalah untuk menganalisis pengaruh disiplin kerja terhadap produktivitas karyawan di Sariasih Garment, untuk menganalisis pengaruh kesehatan kerja terhadap produktivitas kerja karyawan di Sariasih Garment dan untuk menganalisis pengaruh keselamatan kerja terhadap produktivitas kerja karyawan di Sariasih Garment.

Teori yang menyangkut tentang kecelakaan kerja yaitu teori Frank E. Bird. Teori yang dipaparkan oleh Frank E. Bird. Fokus utama teori ini dikemukakan bahwa kecelakaan terjadi karena adanya kesalahan pada manajemen sistem. Untuk memperjelas penelitian ini, bahwa ada pengaruh disiplin kerja, kesehatan kerja, keselamatan kerja terhadap produktivitas kerja. Maka, berdasarkan kajian empiris yang ada bahwa salah satu faktor yang mampu meningkatkan produktivitas secara drastis adalah disiplin karyawan (Hanafi et al., 2015). Produktivitas kerja akan terus meningkat apabila karyawan atau pekerja selalu disiplin dalam bekerja. Tercapainya tujuan perusahaan yang efektif dan efisien tidak terlepas dari displin karyawan yang harus diperhatikan oleh perusahaan (Harlie, 2017). Mangkunegara \& Octorend (2015) menyatakan bahwa untuk mencapai tujuan organisasi diperlukan suatu sikap kedisiplinan kerja karyawan agar produktivitas kerja dari masing-masing karyawan tersebut dapat ditingkatkan dan akhirnya produktivitas kerja karyawan akan meningkat secara keseluruhan. Penelitian Ananta \& Adnyani (2016), menyatakan bahwa disiplin kerja baik secara parsial maupun bersama-sama berpengaruh terhadap produktivitas kerja karyawan. Rahmi \& Wibowo (2019) bahwa keselamatan kerja berpengaruh signifikan terhadap produktivitas kerja karyawan menyatakan bahwa salah satu tujuan dari program keselamatan kerja adalah demi tercapainya peningkatan produktivitas kerja.

Penelitian Elqadri et al. (2015) menyatakan bahwa disiplin kerja berpengaruh positif dan signifikan terhadap produktivitas kerja karyawan dan merupakan variabel yang paling dominan. Penelitian Usman (2016) juga menyatakan bahwa disiplin kerja berpengaruh signifikan terhadap produktivitas kerja, namun dalam hal ini korelasi antara variabel disiplin kerja masih sangat lemah terhadap produktivitas kerja di PT. ALLO JAYA Bontang. Selain itu penelitian Christian \& 
Farida (2016) menyatakan bahwa terdapat pengaruh positif dan signifikan antara disiplin kerja dan produktivitas kerja karyawan bagian produksi Pabrik Kelapa Sawit PT. Perkebunan Nusantara V.

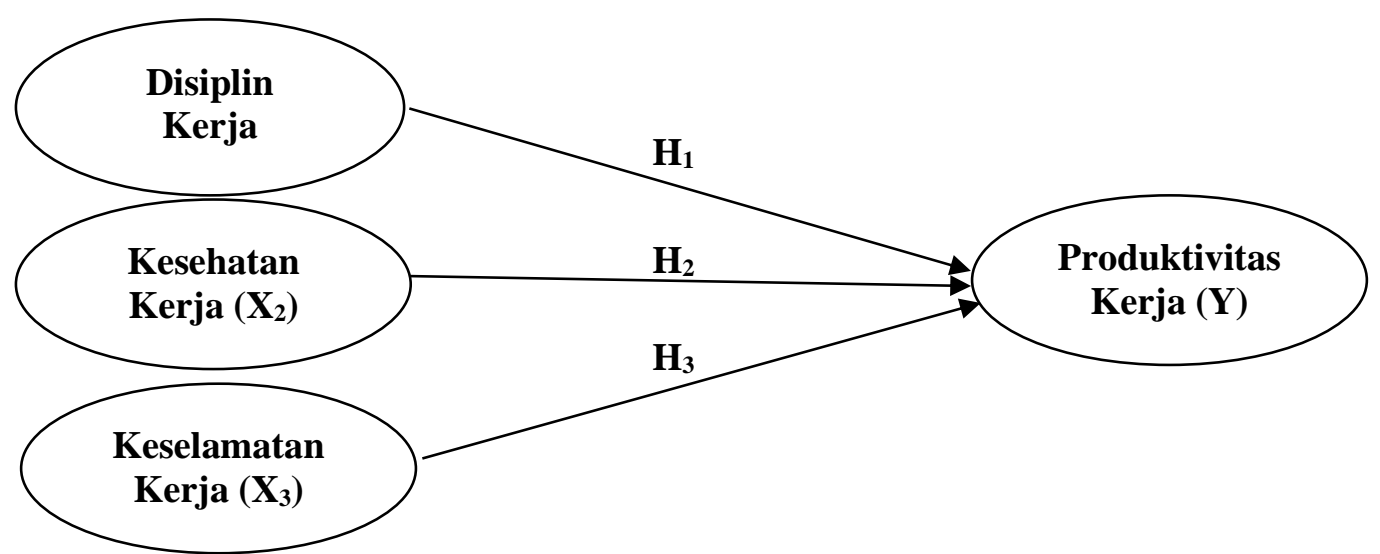

Gambar 2. Kerangka Konseptual Penelitian

Selain itu penelitian Ananta \& Adnyani (2016) menyatakan bahwa disiplin kerja berpengaruh positif dan signifikan terhadap produktivitas dan menjadi variabel yang berpengaruh dominan terhadap produktivitas kerja karyawan. Jika karyawan sering mendapatkan keringanan dari kesalahan yang dilakukan, hal ini akan menyebabkan tingkat kedisiplinan karyawan menurun dikarenakan tidak ada rasa takut yang dimiliki. Untuk itu perlu diberlakukan peraturan yang ketat dan tertulis sehingga dapat dipertanggung jawabkan. Penelitian Irwanto \& Wulandari (2018) juga menyatakan bahwa disiplin kerja berpengaruh positif dan signifikan terhadap produktivitas kerja pegawai pada kantor Pelayanan Bendahara Negara. Penelitian Jung (2016) juga menyatakan bahwa disiplin kerja berpengaruh positif terhadap produktivitas kerja karena dipengaruhi oleh beberapa faktor seperti, karakteristik pribadi, beban kerja, dan karaktertistik perusahaan. Berdasarkan penelitian dan teori sebelumnya, maka dapat disusun hipotesis sebagai berikut:

$\mathrm{H}_{1}$ : Disiplin kerja berpengaruh positif dan signifikan terhadap produktivitas kerja

Penelitian Olouch et al. (2017) menemukan bahwa kesehatan berpengaruh positif dan signifikan terhadap produktivitas kerja karyawan. Karena program kesehatan kerja yang baik dan memenuhi syarat akan menguntungkan karyawan dan perusahaan sebab karyawan akan jarang absen, bekerja dengan lingkungan yang lebih menyenangkan, sehingga secara keseluruhan akan mampu bekerja lebih produktif. Penelitian Budiharjo et al. (2017) juga menyatakan bahwa kesehatan berpengaruh positif tetapi tidak signifikan terhadap produktivitas. Salah satu tujuan kesehatan kerja adalah sebagai alat untuk meningkatkan produksi, berlandaskan pada tingkat efisiensi dan produktivitas kerja.

Selain itu penelitian Gubler et al. (2016) mengatakan bahwa kesehatan berpengaruh positif terhadap produktivitas kerja. Karyawan yang kesehatannya terjamin akan bekerja dengan tenang tanpa ada rasa takut akan terjadinya kecelakaan atau terganggunya kesehatan mereka akibat pekerjaan, sehingga hal ini dapat memacu semangat produktivitas karyawan dalam mengerjakan tugas- 
tugasnya. Njihia et al. (2017) dan Prabowo (2018) dalam penelitiannya juga menyatakan bahwa kesehatan kerja berpengaruh positif terhadap produktivitas pada karyawan.

$\mathrm{H}_{2}$ : Kesehatan kerja berpengaruh positif dan signifikan terhadap produktivitas kerja Berdasarkan penelitian Purwanti \& Musadieq (2017), Budiharjo et al. (2017) dan Rahmi \& Wibowo (2019) yang menyatakan bahwa keselamatan berpengaruh positif dan signifikan terhadap produktivitas kerja. Salah satu tujuan dari keselamatan kerja adalah melindungi tenaga kerja atas keselamatannya selama melakukan pekerjaan sehari-hari ditempat kerja untuk kesejahteraan hidup dan peningkatan produktivitas. Penelitian Gubler et al. (2016) dan Njihia et al. (2017) juga menyatakan bahwa keselamatan lebih dominan berpengaruh positif dan signifikan secara parsial terhadap produktivitas kerja karyawan karyawan manufaktur. Penelitian Ramadhany \& Thamrin (2019) menyatakan bahwa keselamatan kerja berpengaruh positif dan signifikan terhadap produktivitas kerja karyawan PT. Maruki International Indonesia. Berdasarkan penelitian dan teori sebelumnya, maka dapat disusun hipotesis sebagai berikut:

$\mathrm{H}_{3}$ :Keselamatan kerja berpengaruh positif dan signifikan terhadap produktivitas kerja

\section{METODE PENELITIAN}

Desain penelitian ini menggunakan metode kuantitatif yang berbentuk asosiatif kausalitas. Lokasi penelitian ini bertempat di Sariasih Garment dengan alamat perusahaan di Jl. Bedugul Gg. 7xx No. 3, Sidakarya, Denpasar Selatan. Untuk lokasi produksi beralamat di Jl. Noja Gg. VI No. 1, Kesiman, Denpasar Timur. Lokasi ini dipilih karena ditemukan masalah-masalah yang terkait dengan disiplin kerja, kesehatan kerja dan keselamatan kerja yang berpengaruh terhadap produktivitas kerja karyawan Sariasih Garment. Selain itu alasan lain yang melatar belakangi peneliti melakukan penelitian di Sariasih Garment adalah adanya akses yang memudahkan peneliti untuk mendapatkan informasi yang dibutuhkan dalam penelitian ini. Subyek dalam penelitian ini adalah seluruh karyawan pada Sariasih Garment yang terdiri dari departemen pembelian, departemen penjualan \& pemasaran, departemen produksi, departemen produksi, departemen administrasi \& keuangan dan departemen pengiriman.

Data kualitatif dalam penelitian ini yaitu gambaran umum obyek penelitian, meliputi: sejarah singkat berdirinya, letak geografis obyek, struktur organisasi, jenis kelamin, pendidikan, dan hasil wawancara pada karyawan Sariasih Garment. Dalam hal ini data kuantitatif adalah:jumlah karyawan, jumlah kecelakaan kerja karyawan di Sariasih Garment. Data primer dalam penelitian ini adalah data yang dikumpulkan secara langsung dari karyawan Sariasih Garment .Populasi dalam penelitian ini adalah seluruh karyawan Sariasih Garment yang berjumlah 51 orang. Metode yang digunakan dalam penentuan sampel adalah metode sampling jenuh. Pengumpulan data dalam penelitian ini dilakukan dengan menggunakan metode Observasi, Wawancara dan Kuesioner 


\section{HASIL DAN PEMBAHASAN}

Sariasih Garment adalah perusahaan yang bergerak di bidang industri pakaian jadi dari tekstil yang berdiri pada tanggal 26 Juli 2001, didirikan oleh Bapak Komang Tunas Setiawan dan Ibu Ketut Sariani. Sejak berdirinya sampai tahun 2015, Sariasih Garment berlokasi di Jl. Bedugul Gg. 7xx No.3, Sidakarya, Denpasar Selatan. Kemudian pada tahun 2016 tempat produksi Sariasih Garment berpindah lokasi ke Jl. Noja Gg.VI No.1, Kesiman, Denpasar Timur. Hal ini disebabkan karena membutuhkan lahan yang lebih luas untuk tempat produksi karena tingginya angka permintaan dari konsumen. Sariasih Garment memiliki Surat Ijin Usaha dari Dinas Penanaman Modal dan Pelayanan Terpatu Satu Pintu dengan Nomor. 0616/22-09/PK/VIII/2017 atas nama penanggung jawab yaitu I Komang Tunas Setiawan pada tanggal 08 Agustus 2017

Sariasih Garment dilengkapi dengan mesin 10 mesin jahit dengan berbagai merk dan fungsi, 8 diantaranya digunakan sebagai mesin jahit pakaian dan 2 sisanya digunakan sebagai mesin jahit tas. Dilengkapi juga dengan 4 mesin obras, 5 mesin potong, 4 mesin kancing dan beberapa alat yang sehubungan dengan kegiatan menjahit.

Sariasih Garment melayani berbagai kebutuhan seragam, baik seragam sekolah, kantor dan berbagai instansi lainnya. Sariasih Garment pada awalnya menggunakan sistem job order cost. Job order cost merupakan sistem produksi yang apabila ada pesanan atau order dari konsumen maka barang baru akan diproduksi. Namun saat ini Sariasih Garment sudah menjadi salah satu produsen pakaian di Krisna Oleh-Oleh. Meskipun begitu Sariasih Garment masih menerima sistem job order cost.

Tabel 3.

Karakteristik Responden Berdasarkan Jenis Kelamin

\begin{tabular}{cccc}
\hline No & Jenis Kelamin & Jumlah Karyawan (orang) & $\begin{array}{c}\text { Persentase } \\
(\boldsymbol{\%})\end{array}$ \\
\hline 1 & Laki-Laki & 16 & 31,37 \\
2 & Perempuan & 35 & 68,63 \\
& Total & $\mathbf{5 1}$ & $\mathbf{1 0 0}$ \\
\hline
\end{tabular}

Sumber: Data Diolah, 2019

Responden di dominasi oleh perempuan yaitu sebanyak 35 orang atau 68,63 persen dari 51 responden, sedangkan sisanya laki-laki sebanyak 16 orang atau 31,37 persen. Hal ini dikarenakan kemampuan yang dimiliki oleh perempuan di Sariasih Garment.

Sebagian besar responden berusia di antara 25 - 34 tahun dengan persentase sebesar 47,06, sedangkan untuk kelompok usia terendah yaitu ada usia $>41$ tahun dengan persentase 9,80. Hal ini menunjukkan bahwa karyawan di Sariasih Garment didominasi oleh karyawan dengan usia produktif yaitu 25 34 tahun. 
Tabel 4.

Karakteristik Responden Berdasarkan Usia

\begin{tabular}{cccc}
\hline No & Usia & Jumlah Orang & Persentase(\%) \\
& & 8 & 15,69 \\
2 & $19-24$ Tahun & 24 & 47,06 \\
$25-34$ Tahun & 14 & 27,45 \\
3 & $35-40$ Tahun & 5 & 9,80 \\
& $>41$ Tahun & $\mathbf{5 1}$ & $\mathbf{1 0 0}$ \\
\hline
\end{tabular}

Sumber: Data Diolah, 2019

Tabel 5.

Karakteristik Responden Berdasarkan Pendidikan Terakhir

\begin{tabular}{cccc}
\hline No & Pendidikan & Jumlah Orang & $\begin{array}{c}\text { Persentase } \\
(\mathbf{\%})\end{array}$ \\
\hline 1 & SMA & 28 & 54,90 \\
2 & Diploma & 20 & 39,22 \\
3 & S1 & 3 & 5,88 \\
& Total & $\mathbf{5 1}$ & $\mathbf{1 0 0}$ \\
\hline
\end{tabular}

Sumber: Data Diolah, 2019

Sebagian besar responden berdasarkan pendidikan terakhir adalah SMA sebanyak 28 orang dengan persentase sebesar 54,90, sedangkan sisanya Diploma sebanyak 20 orang dengan persentase sebesar 39,22, dan kelompok pendidikan S1 memiliki tingkat responden sebanyak 3 orang dengan persentase 5,88 persen. Hal ini menunjukkan bahwa karyawan di Sariasih Garment sebagian besar berpendidikan SMA yang memiliki keahlian dan kemampuan tentang garment.

Tabel 6.

Hasil Uji Reliabilitas Instrumen Penelitian

\begin{tabular}{lcc}
\hline No. & Variabel & Cronbach's Alpha \\
\hline 1. & Disiplin Kerja (X1) & 0,957 \\
2. & Kesehatan Kerja (X2) & 0,985 \\
3. & Keselamatan Kerja (X3) & 0,969 \\
4. & Produktivitas Kerja (Y) & 0,975 \\
\hline
\end{tabular}

Sumber: Data Diolah, 2019

Uji reliabilitas pada masing-masing variabel berada pada titik diatas 0,60 yang ditunjukkan pada hasil Croanbach's Alpha, maka dapat dikatakan seluruh instrumen telah memenuhi syarat reliabilitas atau kehandalan sehingga dapat digunakan untuk melakukan penelitian.

Seluruh instrumen variabel penelitian berupa disiplin kerja, kesehatan kerja, keselamatan kerja, dan produktivitas kerja telah memenuhi syarat uji validitas yang dimana nilai skor total Pearson Correlation masing-masing instrumen berada di 
atas 0,30 dan memiliki nilai signifikansi yang lebih kecil dari 5\% $(0,05)$, maka instrumen valid dan layak digunakan sebagai instrumen penelitian.

Tabel 7.

Hasil Uji Validitas Instrumen Penelitian

\begin{tabular}{ccc}
\hline Variabel & Item Pernyatan & Pearson Correlation \\
\hline Disiplin Kerja & $\mathrm{X}_{1.1}$ & 0,795 \\
& $\mathrm{X}_{1.1}$ & 0,942 \\
& $\mathrm{X}_{1.2}$ & 0,906 \\
$\mathrm{X}_{1.2}$ & 0,825 \\
& $\mathrm{X}_{1.3}$ & 0,895 \\
$\mathrm{X}_{1.3}$ & 0,925 \\
Kesehatan Kerja & $\mathrm{X}_{1.4}$ & 0,887 \\
& $\mathrm{X}_{1.4}$ & 0,842 \\
& $\mathrm{X}_{2.1}$ & 0,959 \\
& $\mathrm{X}_{2.1}$ & 0,972 \\
& $\mathrm{X}_{2.2}$ & 0,977 \\
& $\mathrm{X}_{2.2}$ & 0,964 \\
& $\mathrm{X}_{2.3}$ & 0,966 \\
& $\mathrm{X}_{2.3}$ & 0,977 \\
& $\mathrm{X}_{3.1}$ & 0,910 \\
& $\mathrm{X}_{3.1}$ & 0,967 \\
& $\mathrm{X}_{3.2}$ & 0,916 \\
Produktivitas Kerja & $\mathrm{X}_{3.2}$ & 0,946 \\
& $\mathrm{X}_{3.3}$ & 0,935 \\
& $\mathrm{X}_{3.3}$ & 0,912 \\
& $\mathrm{Y}_{1}$ & 0,965 \\
& $\mathrm{Y}_{2}$ & 0,961 \\
& $\mathrm{Y}_{3}$ & 0,977 \\
& $\mathrm{Y}_{4}$ & 0,829 \\
& $\mathrm{Y}_{5}$ & 0,972 \\
& $\mathrm{Y}_{6}$ & 0,957 \\
& &
\end{tabular}

Sumber: Data Diolah, 2019

Persepsi responden mengenai variabel produktivitas kerja yang memiliki hasil 3,37 dengan kategori cukup baik. Diantara enam indikator variabel, terdapat tiga indikator yang berada di atas rata-rata yaitu saya menguasai bidang pekerjaan yang saya kerjakan saat ini $\left(\mathrm{Y}_{1}\right)$ sebesar 3,39, selanjutnya indikator saya tidak merasa jenuh dengan pekerjaan yang saya tangani $\left(\mathrm{Y}_{3}\right)$ sebesar 3,41, indikator saya selalu berusaha meningkatkan kualitas kerja saya $\left(\mathrm{Y}_{5}\right)$ sebesar 3,49. Adapun indikator tertinggi ditunjukkan oleh indikator $\left(\mathrm{Y}_{5}\right)$ sebesar 3,49 dan indikator terendah $\left(\mathrm{Y}_{2}\right)$ dan $\left(\mathrm{Y}_{6}\right)$ sebesar 3,29.

Selain indikator yang berada di atas rata-rata, terdapat tiga indikator yang berada dibawah rata-rata, yaitu pekerjaan yang saya hasilkan sudah sesuai dengan targer yang ditetapkan oleh perusahaan $\left(\mathrm{Y}_{2}\right)$ sebesar 3,29, selanjutnya indikator saya selalu berusaha memperbaiki kesalahan yang pernah saya lakukan dalam melaksanakan pekerjaan $\left(\mathrm{Y}_{4}\right)$ sebesar 3,33 dan indikator saya terkadang melebihi batas waktu dalam menyelesaikan pekerjaan $\left(\mathrm{Y}_{6}\right)$ sebesar 3,29. 
Tabel 8.

Deskripsi Penilaian Responden Terhadap Variabel Produktivitas Kerja

\begin{tabular}{|c|c|c|c|c|c|c|c|c|}
\hline & \multirow{2}{*}{ Pernyataan } & \multicolumn{5}{|c|}{ Proporsi Jawaban Responden } & \multirow{2}{*}{$\begin{array}{l}\text { Rata- } \\
\text { rata }\end{array}$} & \multirow[b]{2}{*}{ Kriteria } \\
\hline & & $\begin{array}{l}\text { STS } \\
(1)\end{array}$ & $\begin{array}{l}\text { TS } \\
\text { (2) }\end{array}$ & $\begin{array}{c}\text { RG } \\
(3)\end{array}$ & $\begin{array}{c}S \\
(4)\end{array}$ & $\begin{array}{l}\text { SS } \\
\text { (5) }\end{array}$ & & \\
\hline $\mathrm{Y}_{1}$ & $\begin{array}{l}\text { Saya menguasai bidang } \\
\text { pekerjaan yang saya } \\
\text { kerjakan saat ini. }\end{array}$ & 2 & 10 & 9 & 26 & 4 & 3,39 & $\begin{array}{l}\text { Cukup } \\
\text { Baik }\end{array}$ \\
\hline $\mathrm{Y}_{2}$ & $\begin{array}{l}\text { Pekerjaan yang saya } \\
\text { hasilkan sudah sesuai } \\
\text { dengan target yang } \\
\text { ditetapkan oleh perusahaan }\end{array}$ & 6 & 7 & 11 & 20 & 7 & 3,29 & $\begin{array}{c}\text { Cukup } \\
\text { Baik }\end{array}$ \\
\hline $\mathrm{Y}_{3}$ & $\begin{array}{l}\text { Saya tidak merasa jenuh } \\
\text { terhadap pekerjaan yang } \\
\text { saya tangani }\end{array}$ & 2 & 11 & 6 & 28 & 4 & 3,41 & Baik \\
\hline $\mathrm{Y}_{4}$ & $\begin{array}{l}\text { Saya selalu berusaha } \\
\text { memperbaiki kesalahan } \\
\text { yang pernah saya lakukan } \\
\text { dalam melaksanakan } \\
\text { pekerjaan }\end{array}$ & 0 & 12 & 18 & 13 & 8 & 3,33 & $\begin{array}{l}\text { Cukup } \\
\text { Baik }\end{array}$ \\
\hline $\mathrm{Y}_{5}$ & $\begin{array}{l}\text { Saya selalu berusaha } \\
\text { meningkatkan kualitas kerja } \\
\text { saya }\end{array}$ & 2 & 10 & 7 & 25 & 7 & 3,49 & Baik \\
\hline $\mathrm{Y}_{6}$ & $\begin{array}{l}\text { Saya terkadang melebihi } \\
\text { batas waktu dalam } \\
\text { menyelesaikan pekerjaan }\end{array}$ & 6 & 7 & 11 & 20 & 7 & 3,29 & Baik \\
\hline \multicolumn{7}{|c|}{ Rata-rata } & 3,37 & $\begin{array}{c}\text { Cukup } \\
\text { Baik }\end{array}$ \\
\hline
\end{tabular}

Sumber: Data Diolah, 2019

Persepsi responden mengenai variabel disiplin kerja yang memiliki hasil 3,34 dengan kategori cukup baik. Diantara empat indikator variabel dibagi menjadi delapan pernyataan, terdapat empat pernyataan yang berada di atas rata-rata yaitu selama bekerja saya tidak pernah absen $\left(\mathrm{X}_{1.1}\right)$ sebesar 3,42 , selanjutnya pernyataan saya tidak pernah menunda-nunda pekerjaan $\left(\mathrm{X}_{1.2}\right)$ sebesar 3,39 , selanjutnya pernyataan perusahaan memberikan sanksi tegas bagi karyawan yang melanggar peraturan $\left(\mathrm{X}_{1.4}\right)$ sebesar 3,41 , dan saya pernah melanggar peraturan yang telah ditetapkan oleh perusahaan $\left(\mathrm{X}_{1.4}\right)$ sebesar 3,39. Adapun pernyataan tertinggi ditunjukkan oleh pernyataan $\left(\mathrm{X}_{1.1}\right)$ sebesar 3,42 dan pernyataan terendah $\left(\mathrm{X}_{1.3}\right)$ sebesar 3,22. Selain pernyataan yang berada di atas rata-rata, terdapat empat pernyataan yang berada dibawah rata-rata, yaitu saya selalu mengikuti waktu kerja yang ada di perusahaan ini $\left(\mathrm{X}_{1.1}\right)$ sebesar 3,25 , selanjutnya pernyataan saya tidak pernah menunjukkan sikap malas selama bekerja $\left(\mathrm{X}_{1.2}\right)$ sebesar 3,33 , selanjutnya pernyataan saya menggunakan fasilitas yang ada di perusahaan sesuai dengan 
prosedur yang berlaku $\left(\mathrm{X}_{1.3}\right)$ sebesar 3,22, dan saya bersedia membantu rekan kerja apabila dibutuhkan $\left(\mathrm{X}_{1.3}\right)$ sebesar 3,33.

Tabel 9.

Deskripsi Penilaian Responden Terhadap Variabel Disiplin Kerja

\begin{tabular}{|c|c|c|c|c|c|c|c|c|}
\hline & \multirow[b]{2}{*}{ Pernyataan } & \multicolumn{5}{|c|}{ Proporsi Jawaban Responden } & \multirow{2}{*}{$\begin{array}{c}\text { Rata- } \\
\text { rata }\end{array}$} & \multirow[b]{2}{*}{ Kriteria } \\
\hline & & $\begin{array}{l}\text { STS } \\
(1)\end{array}$ & $\begin{array}{l}\text { TS } \\
(2)\end{array}$ & $\begin{array}{l}\text { RG } \\
(3)\end{array}$ & $\begin{array}{c}S \\
(4)\end{array}$ & $\begin{array}{l}\text { SS } \\
(5)\end{array}$ & & \\
\hline $\mathrm{X}_{1.1}$ & $\begin{array}{l}\text { Selama bekerja saya tidak } \\
\text { pernah absen }\end{array}$ & 0 & 11 & 13 & 21 & 6 & 3,42 & Baik \\
\hline $\mathrm{X}_{1.1}$ & $\begin{array}{l}\text { Saya selalu mengikuti } \\
\text { waktu kerja yang ada di } \\
\text { perusahaan ini }\end{array}$ & 3 & 12 & 7 & 27 & 2 & 3,25 & $\begin{array}{l}\text { Cukup } \\
\text { Baik }\end{array}$ \\
\hline $\mathrm{X}_{1.2}$ & $\begin{array}{l}\text { Saya tidak pernah } \\
\text { menunjukkan sikap malas } \\
\text { selama bekerja }\end{array}$ & 3 & 10 & 14 & 15 & 9 & 3,33 & $\begin{array}{l}\text { Cukup } \\
\text { Baik }\end{array}$ \\
\hline $\mathrm{X}_{1.2}$ & $\begin{array}{l}\text { Saya tidak pernah menunda- } \\
\text { nunda pekerjaan }\end{array}$ & 1 & 10 & 15 & 18 & 7 & 3,39 & $\begin{array}{l}\text { Cukup } \\
\text { Baik }\end{array}$ \\
\hline $\mathrm{X}_{1.3}$ & $\begin{array}{l}\text { Saya menggunakan fasilitas } \\
\text { yang ada di perusahaan } \\
\text { sesuai dengan prosedur yang } \\
\text { berlaku }\end{array}$ & 5 & 10 & 9 & 23 & 4 & 3,22 & $\begin{array}{l}\text { Cukup } \\
\text { Baik }\end{array}$ \\
\hline $\mathrm{X}_{1.3}$ & $\begin{array}{l}\text { Saya bersedia membantu } \\
\text { rekan kerja apabila } \\
\text { dibutuhkan }\end{array}$ & 3 & 11 & 8 & 25 & 4 & 3,31 & $\begin{array}{l}\text { Cukup } \\
\text { Baik }\end{array}$ \\
\hline $\mathrm{X}_{1.4}$ & $\begin{array}{l}\text { Perusahaan memberikan } \\
\text { sanksi tegas bagi karyawan } \\
\text { yang melanggar peraturan }\end{array}$ & 3 & 9 & 15 & 12 & 12 & 3,41 & Baik \\
\hline $\mathrm{X}_{1.4}$ & $\begin{array}{l}\text { Saya pernah melanggar } \\
\text { peraturan yang telah } \\
\text { ditetapkan oleh perusahaan }\end{array}$ & 1 & 11 & 9 & 27 & 3 & 3,39 & $\begin{array}{l}\text { Cukup } \\
\text { Baik }\end{array}$ \\
\hline \multicolumn{7}{|c|}{ Rata-rata } & 3,34 & $\begin{array}{c}\text { Cukup } \\
\text { Baik }\end{array}$ \\
\hline
\end{tabular}

Sumber: Data Diolah, 2019

Persepsi responden mengenai variabel kesehatan kerja yang memiliki hasil 3,28 dengan kategori cukup baik. Diantara tiga indikator variabel dibagi menjadi enam pernyataan, terdapat dua pernyataan yang berada di atas rata-rata yaitu setiap karyawan yang bekerja berada dalam kondisi lingkungan kerja yang aman dan bersih $\left(\mathrm{X}_{2.1}\right)$ sebesar 3,33, dan perusahaan menyediakan obat-obatan untuk 
pertolongan pertama apabila terjadi kecelakaan $\left(\mathrm{X}_{2.3}\right)$ sebesar 3,33. Adapun pernyataan tertinggi ditunjukan oleh pernyataan $\left(\mathrm{X}_{2.1}\right)$ dan $\left(\mathrm{X}_{2.3}\right)$ sebesar 3,33 dan pernyataan terendah $\left(\mathrm{X}_{2.1}\right)$ dan $\left(\mathrm{X}_{2.3}\right)$ sebesar 3,24. Selain pernyataan yang berada di atas rata-rata, terdapat empat pernyataan yang berada di bawah rata-rata yaitu perusahaan menyediakan ventilasi di tempat kerja $\left(\mathrm{X}_{2.1}\right)$ sebesar 3,24, selanjutnya pernyataan tindakan pencegahan penyakit perlu dilakukan oleh perusahaan terhadap karyawan $\left(\mathrm{X}_{2.2}\right)$ sebesar 3,27, selanjutnya pernyataan saya selalu menjaga pola makan $\left(\mathrm{X}_{2.3}\right)$ sebesar 3,24 dan saya selalu merasa bugar pada saat bekerja $\left(\mathrm{X}_{2.3}\right)$ sebesar 3,27.

Tabel 10.

Deskripsi Penilaian Responden Terhadap Variabel Kesehatan Kerja

\begin{tabular}{|c|c|c|c|c|c|c|c|c|}
\hline \multirow{2}{*}{\multicolumn{2}{|c|}{ Pernyataan }} & \multicolumn{5}{|c|}{ Skor Jawaban } & \multirow{2}{*}{$\begin{array}{l}\text { Rata- } \\
\text { rata }\end{array}$} & \multirow[b]{2}{*}{ Kriteria } \\
\hline & & $\begin{array}{c}\text { STS } \\
(1)\end{array}$ & $\begin{array}{l}\text { TS } \\
\text { (2) }\end{array}$ & $\begin{array}{l}\text { RG } \\
\text { (3) }\end{array}$ & $\begin{array}{c}\text { S } \\
(4)\end{array}$ & $\begin{array}{l}\text { SS } \\
(\mathbf{5})\end{array}$ & & \\
\hline $\mathrm{X}_{2.1}$ & $\begin{array}{l}\text { Setiap karyawan yang } \\
\text { bekerja berada dalam } \\
\text { kondisi lingkungan kerja } \\
\text { yang aman dan bersih }\end{array}$ & 4 & 11 & 6 & 24 & 6 & 3,33 & $\begin{array}{l}\text { Cukup } \\
\text { Baik }\end{array}$ \\
\hline $\mathrm{X}_{2.1}$ & $\begin{array}{l}\text { Perusahaan menyediakan } \\
\text { ventilasi di tempat kerja }\end{array}$ & 6 & 11 & 6 & 21 & 7 & 3,24 & $\begin{array}{l}\text { Cukup } \\
\text { Baik }\end{array}$ \\
\hline $\mathrm{X}_{2.2}$ & $\begin{array}{l}\text { Tindakan pencegahan } \\
\text { penyakit perlu dilakukan } \\
\text { oleh perusahaan terhadap } \\
\text { karyawan }\end{array}$ & 2 & 14 & 9 & 20 & 6 & 3,27 & $\begin{array}{l}\text { Cukup } \\
\text { Baik }\end{array}$ \\
\hline $\mathrm{X}_{2.2}$ & $\begin{array}{l}\text { Perusahaan menyediakan } \\
\text { obat-obatan untuk } \\
\text { pertolongan pertama } \\
\text { apabila terjadi kecelakaan }\end{array}$ & 2 & 13 & 6 & 26 & 4 & 3,33 & $\begin{array}{l}\text { Cukup } \\
\text { Baik }\end{array}$ \\
\hline $\mathrm{X}_{2.3}$ & $\begin{array}{l}\text { Saya selalu menjaga pola } \\
\text { makan }\end{array}$ & 3 & 14 & 6 & 24 & 4 & 3,24 & $\begin{array}{l}\text { Cukup } \\
\text { Baik }\end{array}$ \\
\hline $\mathrm{X}_{2.3}$ & $\begin{array}{l}\text { Saya selalu merasa bugar } \\
\text { pada saat bekerja }\end{array}$ & 1 & 16 & 8 & 20 & 6 & 3,27 & $\begin{array}{l}\text { Cukup } \\
\text { Baik }\end{array}$ \\
\hline \multicolumn{7}{|c|}{ Rata-rata } & 3,28 & Cukup Baik \\
\hline
\end{tabular}

Sumber: Data Diolah, 2019

Persepsi responden mengenai variabel keselamatan kerja yang memiliki hasil 3,47 dengan kategori baik. Diantara tiga indikator variabel dibagi menjadi enam pernyataan, terdapat empat pernyataan yang berada di atas rata-rata yaitu semua bagian dari peralatan yang berbahaya telah diberi tanda-tanda $\left(\mathrm{X}_{3.1}\right)$ sebesar 3,47, selanjutnya pernyataan semua peralatan kerja dalam kondisi baik layak pakai $\left(\mathrm{X}_{3.2}\right)$ sebesar 3,47, selanjutnya pernyataan pemilihan alat sesuai dengan pekerjaan saya $\left(\mathrm{X}_{3.2}\right)$ sebesar 3,47 dan perusahaan memberikan petunjuk kerja yang dapat 
mempermudah pekerjaan saya $\left(\mathrm{X}_{3.3}\right)$ sebesar 3,59. Adapun pernyataan tertinggi ditunjukan oleh pernyataan $\left(X_{3.3}\right)$ 3,59 dan pernyataan terendah $\left(X_{3.3}\right)$ sebesar 3,39. Selain pernyataan yang berada di atas rata-rata, terdapat dua pernyataan yang berada di bawah rata-rata yaitu perusahaan selalu menyediakan alat pelindung diri di tempat kerja $\left(\mathrm{X}_{3.1}\right)$ sebesar 3,45 dan penyampaian kendala yang dihadapi karyawan di perusahaan $\left(\mathrm{X}_{3.3}\right)$ sebesar 3,39.

Tabel 11.

Deskripsi Penilaian Responden Terhadap Variabel Keselamatan Kerja

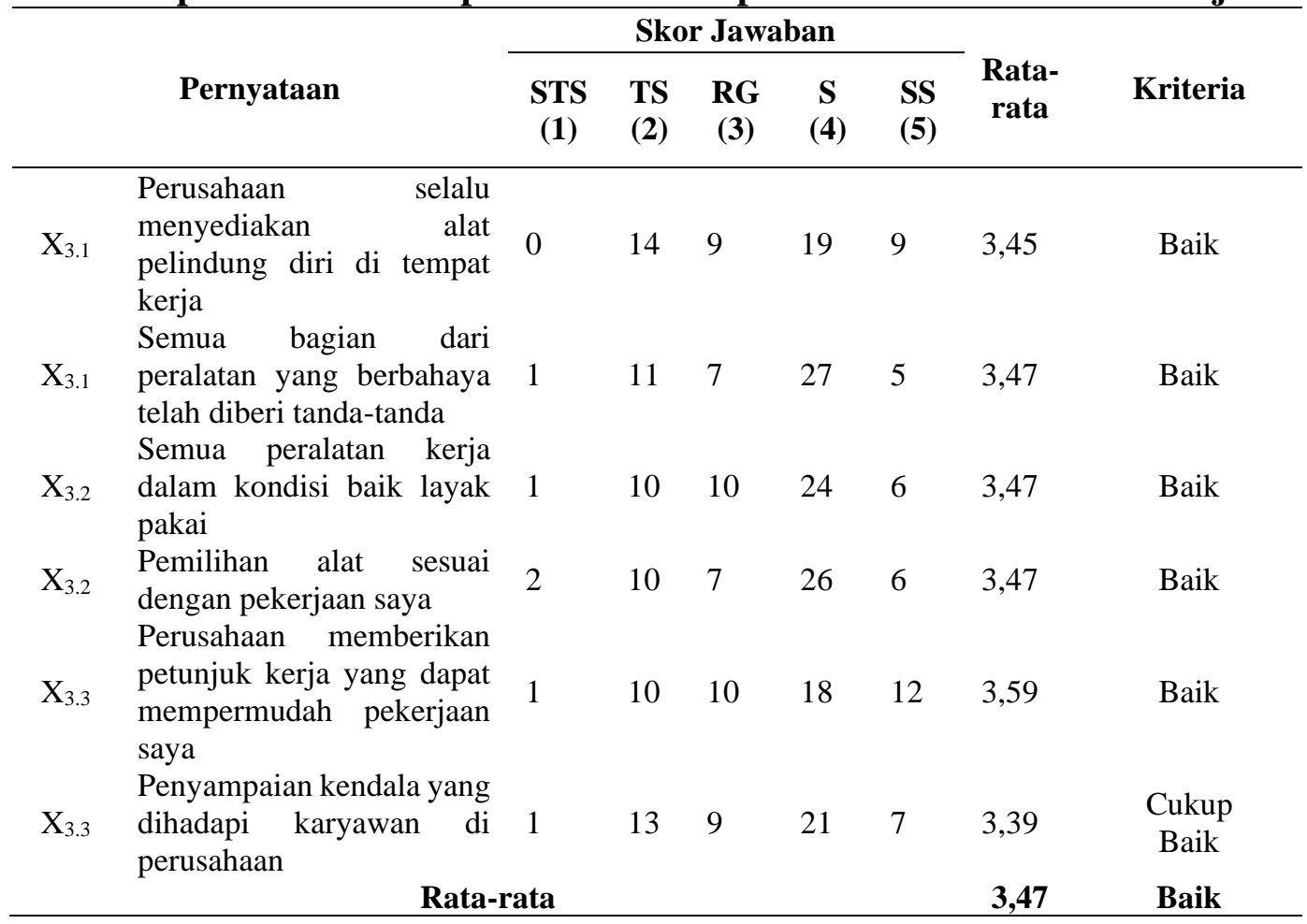

Sumber: Data Diolah, 2019

Tabel 12.

Rangkuman Hasil Analisis Regresi Linear Berganda

\begin{tabular}{|c|c|c|c|c|c|}
\hline \multirow{2}{*}{ Model } & \multicolumn{2}{|c|}{$\begin{array}{l}\text { Unstandardized } \\
\text { Coefficients }\end{array}$} & \multirow{2}{*}{$\begin{array}{c}\begin{array}{c}\text { Standardized } \\
\text { Coefficients }\end{array} \\
\text { Beta }\end{array}$} & \multirow[t]{2}{*}{$\mathbf{t}$} & \multirow[t]{2}{*}{ Sig. } \\
\hline & B & Std. Error & & & \\
\hline (Constant) & -0.008 & 0.396 & & -0.021 & 0.983 \\
\hline Disiplin kerja & 0.423 & 0.109 & 0.390 & 3.868 & 0.000 \\
\hline Kesehatan kerja & 0.285 & 0.118 & 0.299 & 2.412 & 0.020 \\
\hline Keselamatan kerja & 0.296 & 0.133 & 0.279 & 2.221 & 0.031 \\
\hline
\end{tabular}

Nilai constant -0,008 menunjukan apabila disiplin kerja, kesehatan kerja dan keselamatan kerja bernilai sama dengan 0 (nol), maka produktivitas kerja karyawan Sariasih Garment bernilai sebesar -0,008. Koefisien regresi X1 sebesar 0,423, nilai tersebut menunjukkan bahwa disiplin kerja berpengaruh positif 
terhadap produktivitas kerja karyawan Sariasih Garment, apabila disiplin kerja meningkat maka produktivitas kerja karyawan akan mengalami peningkatan sebesar 0,423, begitu pula sebaliknya. Koefisien regresi X2 sebesar 0,285, nilai tersebut menunjukkan bahwa kesehatan kerja berpengaruh positif terhadap produktivitas kerja karyawan Sariasih Garment, apabila kesehatan kerja karyawan meningkat maka produktivitas kerja karyawan akan mengalami peningkatan sebesar 0,285, begitu pula sebaliknya. Koefisien regresi X3 sebesar 0,296, nilai tersebut menunjukkan bahwa keselamatan kerja berpengaruh positif terhadap produktivitas kerja karyawan Sariasih Garment, apabila keselamatan kerja karyawan meningkat maka produktivitas kerja karyawan akan mengalami peningkatan sebesar 0,296 , begitu pula sebaliknya. Nilai $\mathrm{R}^{2}=62,8$ persen, yang berarti bahwa sebesar 62,8 persen produktivitas kerja karyawan Sariasih Garment dipengaruhi oleh variabel disiplin kerja (X1), kesehatan kerja (X2), dan keselamatan kerja (X3) dan sisanya sebesar 37,2 persen dipengaruhi oleh variabel lain yang tidak dimasukan dalam model penelitian ini.

Tabel 13.

Hasil Uji F

\begin{tabular}{llccccc}
\hline & Model & Sum of Squares & df & Mean Square & F & Sig. \\
\hline \multirow{2}{*}{1} & Regression & 33.575 & 3 & 11.192 & 26.459 & $0.000 \mathrm{~b}$ \\
& Residual & 19.880 & 47 & 0.423 & & \\
& Total & 53.456 & 50 & & & \\
\hline
\end{tabular}

Sumber: Data Diolah, 2019

Berdasarkan hasil analisis, diketahui nilai signifikansi $\mathrm{F}$ adalah $0,000<0,05$, maka $\mathrm{H}_{0}$ ditolak. Hal ini berarti bahwa variabel Disiplin kerja $\left(\mathrm{X}_{1}\right)$, variabel Kesehatan kerja $\left(\mathrm{X}_{2}\right)$, variabel Keselamatan kerja $\left(\mathrm{X}_{3}\right)$, secara simultan berpengaruh signifikan terhadap Produktivitas kerja karyawan (Y) Sariasih Garment, atau model yang digunakan dalam penelitian layak dan dapat dipergunakan untuk analisis berikutnya.

Tabel 14.

Hasil Uji t

\begin{tabular}{ccc}
\hline Variabel & Unstandardized Coefficients Beta & Sig. \\
\hline Disiplin kerja & 0,423 & 0,000 \\
Kesehatan kerja & 0,285 & 0,020 \\
Keselamatan kerja & 0,296 & 0,031 \\
\hline
\end{tabular}

Sumber: Data Diolah, 2019

Pengolahan data SPSS menyatakan bahwa terdapat pengaruh positif dan signifikan antara disiplin kerja terhadap produktivitas kerja karyawan Sariasih Garment. Koefisien variabel $\mathrm{X}_{1}$ adalah positif artinya disiplin kerja berpengaruh positif terhadap produktivitas kerja karyawan. Hal ini ditunjukan oleh pernyataan $\mathrm{X}_{1.1}$ dimana selama bekerja responden tidak pernah absen. Selain itu pernyataan $\mathrm{X}_{1.2}$ dimana responden tidak pernah menunda-nunda pekerjaan. Pernyataan lain yaitu $\left(\mathrm{X}_{1.4}\right)$ perusahaan memberikan sanksi tegas bagi karyawan yang melanggar peraturan dan responden pernah melanggar peraturan yang ditetapkan oleh 
perusahaan. Hasil penelitian ini mengembangkan penelitian yang dilakukan oleh Ananta \& Adnyani (2016) dan Irwanto \& Wulandari (2018).

Pengolahan data SPSS menyatakan bahwa terdapat pengaruh positif dan signifikan antara kesehatan kerja terhadap produktivitas kerja karyawan Sariasih Garment. Koefisien variabel $\mathrm{X}_{2}$ adalah positif artinya kesehatan kerja berpengaruh positif terhadap produktivitas kerja karyawan. Hal ini ditunjukan oleh pernyataan $\mathrm{X}_{2.1}$ dimana setiap karyawan yang bekerja berada dalam kondisi lingkungan kerja yang aman dan bersih. Pernyataan lain yaitu $\left(\mathrm{X}_{2.3}\right)$ perusahaan menyediakan obat-obatan untuk pertolongan pertama paabila terjadi kecelakaan. Hasil penelitian ini mengembangkan penelitian yang dilakukan oleh Budiharjo et al. (2017) juga menyatakan bahwa kesehatan berpengaruh positif tetapi tidak signifikan terhadap produktivitas. Njihia et al. (2017)) dalam penelitiannya juga menyatakan bahwa kesehatan kerja berpengaruh positif terhadap produktivitas pada karyawan manufaktur. Penelitian Prabowo (2018) juga menyatakan bahwa kesehatan kerja berpengaruh positif dan signifikan terhadap produktivitas kerja karyawan.

Pengolahan data SPSS menyatakan bahwa terdapat pengaruh positif dan signifikan antara keselamatan kerja terhadap produktivitas kerja karyawan Sariasih Garment. Koefisien variabel $\mathrm{X}_{3}$ adalah positif artinya keselamatan kerja berpengaruh positif terhadap produktivitas kerja karyawan. Hal ini ditunjukan oleh pernyataan $\mathrm{X}_{3.1}$ dimana semua bagian peralatan yang berbahaya telah diberi tandatanda. Selain itu pernyataan $\mathrm{X}_{3.2}$ dimana semua perlaatan kerja dalam kondisi baik layak pakai dan pemilihan alat sesuai dengan pekerjaan saya. Pernyataan lain yaitu $\left(\mathrm{X}_{3.4}\right)$ dimana perusahaan memberikan petunjuk kerja yang dapat mempermudah pekerjaan saya.

Hasil pengujian hipotesis dalam penelitian ini menunjukkan bahwa keselamatan kerja memiliki pengaruh positif dan signifikan terhadap produktivitas kerja, artinya semakin aman keselamatan seorang karyawan di Sariasih Garment, maka semakin tinggi tingkat produktivitas kerja karyawan di Sariasih Garment. Hal ini menandakan bahwa kesehatan kerja mampu meningkatkan produktivitas kerja pada diri karyawan sehingga hipotesis ketiga diterima. Hubungan ini didukung oleh teori Frank E. Bird yang berarti bahwa perusahaan harus memperhatikan peralatan atau perlengkapan yang tidak memadai sehingga produktivitas kerja karyawannya tidak menurun akibat kecelakaan yang dapat mengancam keselamatan karyawanya di tempat kerja. Penelitian Ramadhany \& Thamrin (2019) menyatakan bahwa keselamatan kerja berpengaruh positif dan signifikan terhadap produktivitas kerja karyawan PT. Maruki International Indonesia

Implikasi pertama, responden sangat setuju bahwa disiplin kerja mampu meningkatkan produktivitas kerja karyawan. Hal ini terbukti dari indikator disiplin kerja yaitu: mengikuti waktu kerja yang ada diperusahaan. Ketika karyawan bekerja sesuai jam kerja yang ada di perusahaan maka karyawan tersebut dapat meningkatkan produktivitas kerjanya. Oleh sebab itu dibutuhkan pengawasan yang ketat dari atasan pada saat jam bekerja agar karyawan tidak melakukan tindakan tidak disiplin pada saat bekerja. Implikasi kedua, responden sangat setuju bahwa kesehatan kerja mampu meningkatkan produktivitas kerja karyawan. Hal ini terbukti dari indikator kesehatan kerja yaitu: melakukan tindakan pencegahan 
penyakit terhadap karyawan. Ketika perusahaan memberikan perlindungan karyawan berupa tindakan pencegahan terhadap penyakit yang dialami karyawan, maka kesehatan karyawan akan terus terjaga sehingga ia akan bekerja optimal sehingga mampu memberikan hasil kerja yang maksimal. Implikasi ketiga, responden sangat setuju bahwa keselamatan kerja mampu meningkatkan produktivitas kerja karyawan. Hal ini terbukti dari indikator keselamatan kerja yaitu: menyediakan alat pelindung diri di tempat kerja. Ketika karyawan bekerja tanpa alat pelindung diri yang memadai, maka kecelakaan kerja dapat terjadi karena timbulnya bahaya di tempat kerja sehingga membuat karyawan bekerja dalam kondisi kerja yang tidak aman.

\section{SIMPULAN}

Disiplin kerja berpengaruh positif dan signifikan terhadap produktivitas kerja karyawan. Hal ini menunjukkan bahwa jika penerapan disiplin kerja semakin baik maka produktivitas kerja karyawan menjadi semakin meningkat pula. Kesehatan kerja berpengaruh positif dan signifikan terhadap produktivitas kerja karyawan. Hal ini menunjukkan bahwa jika penerapan kesehatan kerja semakin baik maka produktivitas kerja karyawan menjadi semakin meningkat pula. Keselamatan kerja berpengaruh positif dan signfikan terhadap produktivitas kerja karyawan Sariasih Garment. Hal ini menunjukkan bahwa jika keselamatan kerja karyawan baik maka produktivitas karyawan akan meningkat pula.

Secara praktis, pihak manajemen Sariasih Garment harus tetap mempertahankan disiplin kerja, kesehatan kerja dan keselamatan kerja di dalam perusahaan agar karyawan merasa diperhatikan, sehingga akan meningkatkan Produktivitas kerja karyawan Sariasih Garment. Hal yang harus ditingkatkan adalah dari segi disiplin kerja adalah penggunaan fasilitas yang ada di perusahaan sesuai dengan prosedur yang memiliki rata-rata terendah hal ini harus ditingkatkan dengan cara memberikan cctv atau pengawasan agar tidak ada karyawan yang melakukan tindakan tidak disiplin. Dari segi kesehatan kerja hal yang perlu ditingkatkan adalah penyediaan ventilasi di tempat kerja dengan cara membuat ventilasi udara agar sirkulasi udara di dalam ruangan kerja tetap terjaga. Dari segi keselamatan kerja yang perlu ditingkatkan lagi adalah penyampaian kendala yang dihadapi karyawan di perusahaan dengan cara sering melakukan diskusi ataupun mendengar saran dan kritik dari karyawan demi kelangsungan produktivitas di perusahaan tersebut.

Bagi peneliti selanjutnya, diharapkan pada peneliti selanjutnya tidak berpaku pada faktor-faktor dalam penelitian ini yaitu disiplin kerja, kesehatan dan keselamatan kerja, namun dapat menambah faktor-faktor lain yang mungkin mempengaruhi Produktivitas kerja karyawan. Selain itu peneliti selanjutnya diharapkan dapat menambahkan atau menggunakan subjek penelitian lain.

\section{REFERENSI}

Adeyeye, J., Adeniji, A. A., Osinbajo, A. O., \& Oludayo, O. A. (2015). Effects of Workplace Ethics on Employee and Organisational Productivity in Nigeria. International Conference on African Development Issues, 1(1), 267-273. 
Ananta, I. K. F., \& Adnyani, I. G. A. D. (2016). Pengaruh Disiplin Kerja dan Budaya Organisasi Terhadap Produktivitas Kerja Karyawan pada Villa Mahapala Sanur-Denpasar. E-Jurnal Manajemen Unud, 5(2), 1103-1130.

Budiharjo, P. H., Lengkong, V. P. K., \& Dotulong, L. O. H. (2017). Pengaruh Keselamatan Kerja, Kesehatan Kerja, dan Lingkungan Kerja Terhadap Produktivitas Karyawan pada PT. Air Manado. Jurnal EMBA: Jurnal Riset Ekonomi, Manajemen, Bisnis Dan Akuntansi, 3(5), 4145-4154.

Christian, F. A., \& Farida, L. (2016). Pengaruh Disiplin Kerja Terhadpa Produktivitas Kerja Karyawan Bagian Produksi Pabrik Kelapa Sawit PT. Perkebunan Nusantara V Sei Rokan Kec. Pagaran Tapah Darussalam Kab. Rokan Hulu. JOM FISIP, 3(1), 1-15.

Elqadri, Z. N., Wardoyo, D. T. W., \& Priyono. (2015). The Infuence of Motivation and Discipline Work against Employee Work Productivity Tona'an Markets. Review of European Studies, 7(2), 59-66.

Gubler, T., Larkin, I., \& Pierce, L. (2016). The Impact of Corporate Wellness Programs on Employee Productivity. SSRN Electronic Journal, 1(2), 1-20. https://doi.org/10.2139/ssrn.2811785

Hanafi, M. H., Khalid, A. G., Razak, A. A., \& Abdullah, S. (2015). Main Factors Influencing Labour Productivity of The Installation of on-Site Prefabricated Components. International Journal of Academic Research, 2(6), 139-146.

Hanaysha, J. (2016). Testing the Effects of Employee Empowerment, Teamwork, and Employee Training on Employee Productivity in Higher Education Sector. International Journal of Learning \& Development, 6(1), 164-178. https://doi.org/http://dx.doi.org/10.5296/ ijld.v6i1.9200

Harlie, M. (2017). Analisis Faktor yang Mempengaruhi Tingkat Produktivitas Kerja Karyawan (Studi Kasus PT. Surya Satria Timur Corporation Jakarta Pusat). At-Tadbir: Jurnal Ilmiah Manajemen, 1(1), 1-12.

Irwanto, \& Wulandari, R. (2018). Hubungan Disiplin Kerja dengan Produktivitas Kerja Pegawai Pada Kantor Pelayanan Perbendaharaan Negara (KPPN) Langsa. Jurnal Bisnis Administrasi, 7(1), 74-83.

Jung, J. (2016). Faculty Research Productivity in Hong Kong across Academic Discipline. Higher Education Studies, 2(4), 1-13. https://doi.org/http://dx.doi.org/10.5539/hes.v2n4p1.

Mangkunegara, A. P., \& Octorend, T. R. (2015). Effect of Work Discipline, Work Motivation and Job Satisfication on Employee Organizational Commitment ib 
the Company (Case Study in PT. Dada Indonesia). Universal Journal of Management, 3(1), 318-328.

Njihia, E. W., Nzulwa, D. J., \& Kwena, R. (2017). Influence of occupational safety and health on employee productivity in the manufacturing sector in kenya. The Strategic Journal of Business \& Change Management, 4(4), 555-571.

Ofoegobu, G. T., Olawepo, \& Ibojo, B. O. (2015). Effects of Occupational Hazards on Employees Productivity. European Journal of Business and Management, 5(3), 10-21.

Olouch, I., Njogu, P., \& Ndeda, J. O. H. (2017). Effects of Occupational Safety and Health Hazard's Exposuer on Work Environment in the Water Service Industry within Kisumu County-Kenya. IOSR Journal of Environmental Science, Toxicology and Food Technology, 11(1), 46-51.

Prabowo, C. H. (2018). Pengaruh Kesehatan dan Keselamatan Kerja (K3) dan Lingkungan Kerja Terhadap Produktivitas Kerja Karyawan PT. Rickstar Indonesia. Jurnal Manajemen Bisnis Krisnadwipayana, 6(3), 1-11.

Prayitno, H., \& Palupi, R. A. (2015). The Effect of Occupational Safety and Health on Work Productivity of Field Workers of Access Network Maintance at PT. Telkom Kandatel Jember. International Journal of Sciences: Basic and Applied Research, 2(1), 257-262.

Purwanti, L. D., \& Musadieq, M. Al. (2017). Pengaruh Keselamatan dan Kesehatan Kerja Terhadap Kualitas Kehidupan Kerja dan Produktivtias Kerja (Studi pada Karyawan Divisi Operasi dan Pemeliharaan PT. Pembangkitan Jawa Bali (PJB) Unit Pembangkitan Paiton). Jurnal Administrasi Bisnis (JAB), 44(1), 118-126.

Rahmi, T. E., \& Wibowo, S. (2019). The Effect of Physical Work Environment, Work Safety, Occupational Health and Work Discipline on Employee Productivity. Journal of Research in Management, 1(4), 33-41. https://doi.org/10.32424/jorim.v1i4.56

Ramadhany, F., \& Thamrin, Y. (2019). Pengaruh Sistem Manajemen Kesehatan dan Keselamatan Kerja Terhadap Produktivitas Kerja Karyawan PT. Maruki International Indonesia. Jurnal Ilmiah Kesehatan Diagnosis, 14(1), 26-30.

Saleh, A. R. (2018). Pengaruh Disiplin Kerja, Motivasi Kerja, Etos Kerja dan Lingkungan Kerja Terhadap Produktivitas Kerja Karyawan Bagian Produksi PT. Inko Jaya Semarang. Jurnal Among Makarti, 11(21), 28-50.

Sulfikar, dkk. (2015). Factors associated with lung function disturbance to textile industry worker in production department of CV. Bagabs Makasar city. 
International Refereed Journal of Engineering and Science (IRJES) ISSN (Online), 4(1), 2319-183. Retrieved from www.irjes.com

Sultana, A., Irum, S., Ahmed, K., \& Mehmood, N. (2015). Impact of Training on Employee Performance: A Study of Telecomunication Sector in Pakistan. Interdisciplinary Journal of Contemporary Research in Business, 4(6), 646661.

Umeokafor, N., Isaac, D., Jones, K., \& Umeadi, B. (2015). Enforcement of Occupational Safety and Health Regulations in Nigeria: An Exploration. European Scientific Journal, 3(1), 93-104.

Usman, I. (2016). Pengaruh Disiplin Kerja Terhadap Produktivitas Kerja Karyawan PT. Allo Jaya di Bontang. EJournal Administari Bisnis, 4(3), 911-922. 